\title{
A Flórula inVASORA da CULTURA do CAFÉ (Coffea arabica L.) NO ESTADO DE MINAS GERAIS, BRASIL.
}

\author{
Manuel Losada Gavilanes 1 \\ Mitzi Brandão 2 \\ Julio Pedro Laca-Buendia 3
}

\begin{abstract}
RESUMO - (A flórula invasora da cultura do café (Coffea arabica L.) no Estado de Minas Gerais, Brasil). Nas áreas de cultura de café (Coffea arabica L.), no Estado de Minas Gerais, foram coletadas e identificadas 388 espécies de plantas invasoras (= plantas daninhas), pertencentes a 51 famílias botânicas, representando 182 gêneros, sendo que as famílias Compositae, Gramineae, Leguminosae, Malvaceae, Solanaceae, Euphorbiaceae, Rubiaceae, Amaranthaceae, Convolvulaceae e Verbenaceae, são as mais importantes em relação à cultura. As plantas coletadas, devidamente etiquetadas e identificadas, foram anexadas, parte delas no PAMG (Herbário da EPAMIG, Belo Horizonte, MG) e, a outra parte, no Herbarium ESAL (Herbário do Departamento de Biologia da Escola Superior de Agricultura de Lavras - ESAL, Lavras - MG).

Palavras-chave: Coffea arabica, Plantas Daninhas, Daninhas do cafeeiro.
\end{abstract}

\begin{abstract}
Weeds in coffee (Coffea arabica L.) plantations in the state of Minas Gerais, Brazil). A survey in the cultivation area of coffee in the State of Minas Gerais, Brazil, has resulted in the determination of 388 weed species, of 182 genera belonging to 51 families; the families presenting a greater number of especies are: Compositae, Leguminosae, Gramineae, Malvaceae, Solanaceae, Rubiaceae, Convolvulaceae, Euphorbiaceae, Amaranthaceae and Verbenaceae with $65,48,42,30,19,17,16,14,12,10$ species, respectively.

Key words: Coffea arabica, weeds, coffee weeds.
\end{abstract}

\section{Introdução}

A ocorrência de invasoras na agricultura é a causa de consideráveis decréscimos na produtividade das culturas. Nas zonas temperadas, as perdas são da ordem de $10,0 \%$ a $15,0 \%$ da produção agrícola e florestal, e da ordem de 5,0\% nos terrenos não cultivados e ambientes aquáticos, segundo a NATIONAL ACADEMY OF SCIENCES (1968)

Em algumas culturas as produções podem ser reduzidas em mais de 50,0\% devido às invasoras (Mani et al. 1968). Para a América do Sul, Cramer (1967), estudando 14 culturas principais, atribui às plantas invasoras um prejuízo médio de $8,3 \%$.

Pereira \& Jones (1954) encontraram uma diferença de produção de $47 \%$, computando as colheitas de cinco anos, de cafeeiros conservados limpos (capinados) e daqueles que permaneceram com as plantas invasoras.

Segundo Zeep (1971), as invasoras, além de competirem por nutrientes, água, luz ou apenas espaço, podem ser hospedeiras de doenças e pragas e influir na colheita, qualidade e valor mercantil das produções.

Crafts \& Robbins (1962) afirmam que as plantas invasoras constituem a principal causa de prejuizos à produção de alimentos, vindo a seguir as pragas e as doenças das plantas.

\footnotetext{
${ }^{1}$ Professor de Botânica da ESAL, Caixa Postal 37, 37.200 - Lavras, MG. Bolsista do CNPq.

2 Pesquisador da EPAMIG, Caixa Postal 515, 30.000 - Belo Horizonte, MG. Bolsista do CNPq.

3 Pesquisador da EPAMIG, Caixa Postal 515, 30.000 - Belo Horizonte, MG.
} 
O cadastramento efetivo, a identificação, os estudos de fenologia, germinação, desenvolvimento, competição, etc., de plantas daninhas, ocorrentes em pastagens e/ou culturas, no Estado de Minas Gerais, objetivam subsidiar o seu controle ou erradicação, além de oferecer dados reais que permitam o reconhecimento dessas plantas, em nível de campo.

Alguns trabalhos sobre o tema já foram realizados, no Estado, não tendo, entretanto, esgotado o assunto, assim como, efetivado o cadastramento total das espécies ocorrentes no Estado.

Cada nova cultura introduzida, ou lotes de sementes a serem cultivados, provenientes de outros Estados, sempre concorrem com novas contribuições para este acervo, a cada ano.

Torna-se imprescindível o levantamento sistemático dessas plantas por cultura, como também a sua identificação botânica, visto que a maioria dos trabalhos feitos com herbicidas só cita aquelas mais freqüentes e grande parte dos autores só as identifica pelo seu nome genérico, como por exemplo: Zarecor (1979), Street et al. (1981), Maia (1978), Buss (1981) e Marcondes et al. (1981).

Nesta etapa, aquelas da cultura cafeeira são apresentadas.

\section{Antecedentes e Justificativa}

Poucos botânicos em Minas Gerais têm-se ocupado do estudo de e/levantamento das plantas daninhas no Estado.

Warming (1908), em seu trabalho sobre Lagoa Santa, apresenta cerca de 230 espécies para aquela área. $\mathrm{O}$ mesmo autor menciona as famílias Compositae e Gramineae como aquelas que fornecem um número maior de espécies. Leguminosae, Solanaceae, Euphorbiaceae, Labiatae, Malvaceae e Rubiaceae vêm em segundo lugar.

Vianna (1916) faz constar a presença de numerosas ruderais no Município de Montes Claros.

Monteiro (1958) apresenta 10 espécies de Malvaceae invasoras, existentes em culturas no Estado de Minas Gerais.

Goodland (1970) menciona várias plantas daninhas para a área do Triângulo Mineiro, em seu trabalho sobre a vegetação da região.

Vidal \& Vidal $(1965,1967,1971)$ fazem o levantamento das ruderais de Viçosa - MG.

Gentchujnicov et al. (1972) fazem o levantamento fitossociológico de populações de plantas daninhas nos cafezais afetados por Hemileia vastatrix, visitando áreas do Sul de Minas Gerais.

Laca-Buendia; Ferreira \& Gavilanes $(1975,1977,1982)$ listaram as espécies de plantas daninhas que ocorrem na cultura do algodoeiro. Esses mesmos autores estão cuidando do levantamento dessas plantas em áreas de cultura de mandioca, milho e sorgo, feijão e pomares.

Entre os trabalhos gerais publicados sobre plantas daninhas no País, temos os de Kuhlmann et al. (1947), que abordam espécies pertencentes às famílias Solanaceae, Umbelliferae, Malvaceae, Labiatae e Amaranthaceae, apresentando uma série de plantas ocorrentes em Minas Gerais.

Lorenzi (1976) cataloga 260 espécies de plantas daninhas de culturas para o Estado do Paraná, sendo a maioria dessas espécies encontradas em Minas Gerais.

Brandão, Laca-Buendia \& Gavilanes 1982) apresentam uma listagem das principais plantas daninhas que ocorrem em Minas Gerais e culturas onde são citadas. Esses mesmos autores em 1984 listaram as espécies que ocorrem na cultura de soja. 


\section{Objetivos}

São objetivos principais deste trabalho:

A - Proporcionar referências para a identificação das plantas daninhas (Plantas invasoras de culturas), que competem com a cultura do cafeeiro no Estado de Minas Gerais.

B - Dar subsídios aos técnicos em herbicidas, a fim de que possam reconhecer as ervas ocorrentes em culturas de Coffea arabica L. dentro do Estado de Minas Gerais.

C - Continuar, em face de relativa escassez de dados sobre plantas daninhas em terras mineiras, o levantamento das espécies, do ponto de vista botânico, iniciado com o levantamento das plantas daninhas ocorrentes na cultura algodoeira (Laca-Buendia et al. 1975, 1977a, 1977b; Brandão et al. 1982).

D - Apresentar, em trabalho posterior (já em andamento), além das chaves de identificação, um catálogo de sementes, fruto/sementes e plântulas, de plantas daninhas ocorrentes no Estado de Minas Gerais.

\section{Material e Métodos}

Foram coletadas as plantas daninhas ocorrentes em culturas do cafeeiro, durante o período 1979/1983, nas microrregiões 159 (Alto Rio Pardo), 165 (Pastoril de Almenara), 169 (Pastoril de Nanuque), 171 (Alto Paranaíba), 172 (Mata da Corda), 173 (Três Marias), 174 (Bacia do Suaçui), 176 (Mantena), 178 (Uberaba), 179 (Planalto de Araxá),

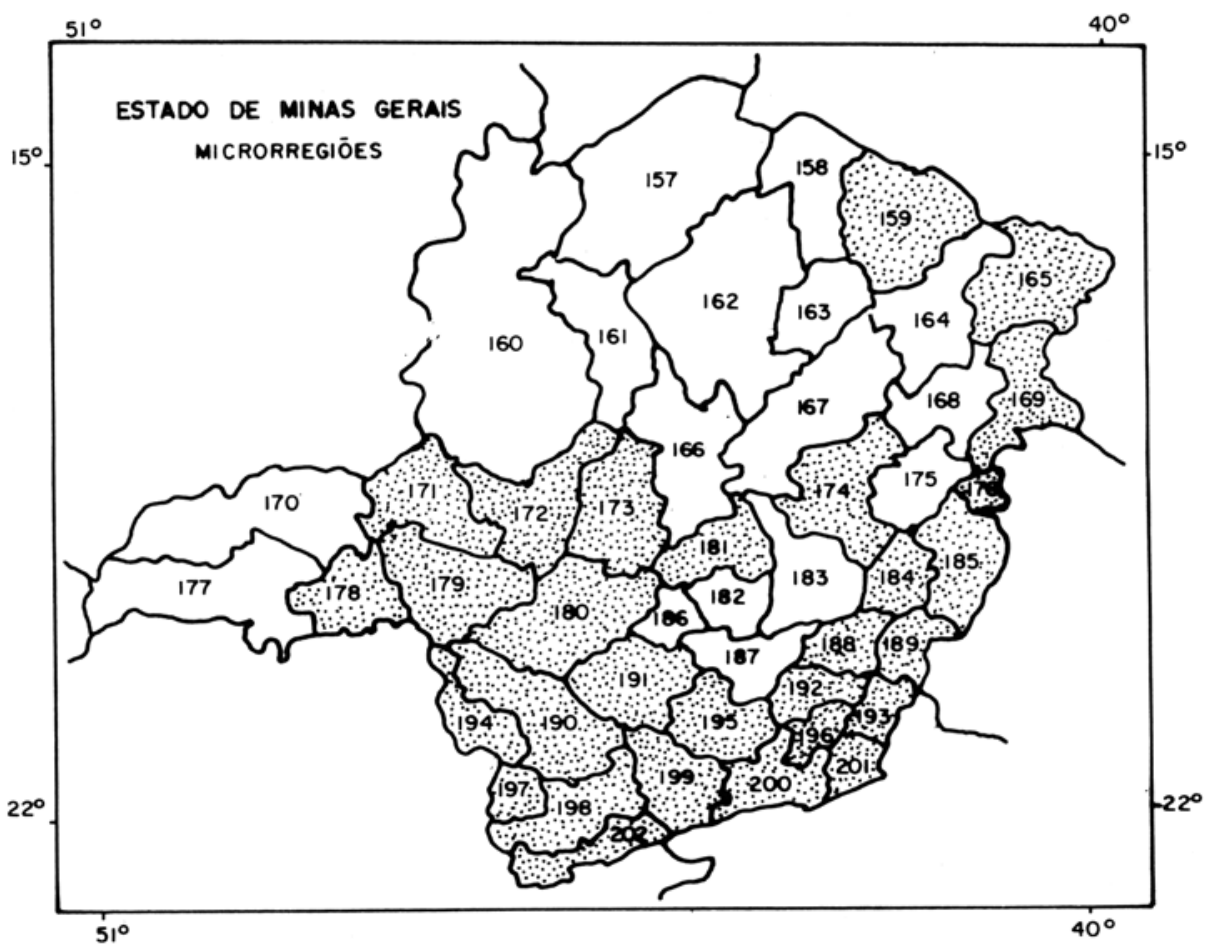

Figura 1. Localização das microrregiōes onde se localizam culturas do cafeeiro (Coffea arabica L.) no Estado de Minas Gerais. 
180 (Alto São Francisco), 181 (Calcáreo de Sete Lagoas), 184 (Mata de Caratinga), 185 (Bacia do Manhuaçu), 188 (Mata de Ponte Nova), 189 (Vertente Ocidental do Caparaó), 190 (Furnas), 191 (Formiga), 192 (Mata de Viçosa), 193 (Mata de Muriaé), 194 (Mogiana Mineira), 195 (Campos da Mantiqueira), 196 (Mata de Ubá), 197 (Planalto de Poços de Caldas), 198 (Planalto Mineiro), 199 (Alto Rio Grande), 200 (Juiz de Fora), 201 (Mata de Cataguases), 202 (Alto da Mantiqueira). (Figura 1).

Em cada microrregião foram percorridos vários municípios e visitadas as fazendas mais representativas do cultivo do cafeeiro. Em cada uma, vários campos distintos foram examinados.

As plantas coletadas foram identificadas, segundo a metodologia clássica, rotuladas, registradas e anexadas ao PAMG (Herbário da EPAMIG) e, também, no Herbarium ESAL.

\section{Resultados}

$\mathrm{Na}$ atual listagem, relacionam-se aquelas plantas daninhas ocorrentes em culturas de café (Coffea arabica L.), no Estado de Minas Gerais.

Foram identificadas 388 espécies de plantas invasoras à cultura do cafeeiro, pertencentes a 51 famílias, representando 182 gêneros. As plantas em questão estão relacionadas na Tabela 1.

Na Tabela 2 as famílias estão ordenadas por ordem alfabética, seguidas de números de gêneros e de espécies encontradas.

Além das espécies que foram coletadas, incluíram-se aquelas relacionadas pela bibliografia consultada e as coletadas e enviadas por terceiros, pertencentes aos experimentos, em andamento dessa cultura, situados em pontos esparsos do Estado.

As famílias mais representativas foram: Compositae com 44 gêneros e 65 espécies, Gramineae com 23 gêneros e 42 espécies, Leguminosae com 16 gêneros e 48 espécies, Malvaceae com 7 gêneros e 30 espécies, Solanaceae com 4 gêneros e 19 espécies, Euphorbiaceae com 4 gêneros e 14 espécies, Rubiaceae com 5 gêneros e 17 espécies, Amaranthaceae com 4 gêneros e 12 espécies, Convolvulaceae com 2 gêneros e 16 espécies e Verbenaceae com 3 gêneros e 10 espécies.

\section{Conclusões}

O cafeeiro é uma planta exigente em termos de solos, geralmente apreciando aqueles profundos, férteis e bem drenados, como os Podzólicos e Latossolos. Em função dessa mesma fertilidade e de ocupar áreas de climas mais amenos no Estado, esses fatores condicionam o aparecimento de um número mais elevado de plantas invasoras, quando se compara com outras culturas, conforme a listagem em anexo vem confirmar.

O uso do binômio completo, isto é, a identificação taxonômica correta de uma espécie, vem esclarecer uma série de problemas impostos, mas não devidamente explicados pelos autores, ou seja, aqueles do comportamento e desenvolvimento da espécie visada em seus trabalhos. Espécies distintas, pertencentes ao mesmo gênero, podem ter hábitos completamente diversos e, portanto, formas variadas de ação sobre as plantas com as quais competem. Por exemplo, uma planta de hábito escandente compete, em termos de luz, muito mais que uma de hábito ereto. Os tipos de raiz, a forma de sua distribuição, a rapidez de seu desenvolvimento e o ciclo evolutivo de certas espécies podem exigir uma-soma maior de nutrientes e, portanı, ser competidoras em outro nível com as plantas cultivadas.

Sendo a citação corretamente feita, tem-se outra visão dos reais efeitos da competição, da forma da competição, do conhecimento do comportamento da planta em enfoque, facilitando, por outro lado, uma seleção prévia daquelas mais competidoras, tendo 
como resultado pesquisas adequadas que visam ao controle e à erradicação dessas espécies com o uso de herbicidas seletivos.

O presente trabalho terá continuidade com o "Catálogo de sementes, fruto/semente e plântulas de plantas daninhas ocorrentes em culturas de café (Coffea arabica L.), no Estado de Minas Gerais", dando seqüência à série de “Catálogos ilustrados”, iniciada com o de plantas daninhas de pastagens (Ferreira et al. 1981) e, posteriormente, com o de plantas daninhas da cultura algodoeira (Brandão et al. 1983).

Outros “C̣atálogos" serão realizados, desde que as listagens prévias, específicas por culturas, já existentes e publicadas (Brandão et al. 1982), achem-se devidamente atualizadas.

\section{Referências Bibliográficas}

BRANDÃO, M.; LACA-BUENDIA, J. P. \& GAVILANES, M. L. 1982. Principais plantas daninhas no Estado de Minas Gerais. Inf. Agropecu., Belo Horizonte, 8 (87): 18-26.

BRANDÃO, M.; LACA-BUENDIA, J. P.; SOUZA CUNHA, L. H. de \& GAVILANES, M. L. 1913 Catálogo ilustrado de frutos, frutos/sementes, sementes e plântulas de plantas daninhas ocorrentes na cultura algodoeira no Estado de Minas Gerais e herbicidas utilizadas para seu controle. Belo Horizonte, EPAMIG. (Documentos, 12)

BUSS, A. 1981. As plantas daninhas mais comuns nas lavouras de soja. In: MIYSAKAS, S. \& MEDINA, J. C. (ed.). (A soja do Brasil, Campinas, ITAL. p. 536-41.

CRAFTS, A. S. \& ROBBINS, W. N. 1962. Weeds control. New York, MacGraw Hill. 323p.

CRAMER, H. H. 1967. Defensa vegetal y cosecha mundial. Bayer Pflanzenschutz Leverkusen.

FERREIRA, M. B. et al. 1981. Catálogo ilustrado de sementes e frutos/sementes, de plantas daninhas ocorrentes em pastagens, no Estado de Minas Gerais e, herbicidas utilizadas para seu côntrole. Belo Horizonte EPAMIG.

GEMTCHUJNICOV, I.; ALMEIDA, F. M. \& GOMES, P. F. 1972. Levantamento fitossociológico de populações de plantas daninhas em cafezais atacados por Hemileia vastatrix. In: CONGRESSO NACIONAL DE BOTÂNICA, 23, Garanhuns. Anais..., Garanhuns, p. 203-223.

GOODLAND, R. J. A. 1970 Plant of the cerrado vegetation of Brazil. Phytologia, New York, 7:41-133.

KUHLMANN, J. G. et al. 1947. Contribuição ao estudo das plantas ruderais do Brasil. Arq. Jard. Bot. Rio de Janeiro, Rio de Janeiro, 7:43-133.

LACA-BUENDIA, J. P.; FERREIRA, M. B. \& GAVILANES, M. L. 1975. Contribuição para o conhecimento das ervas daninhas nas principais regiões algodoeiras do Estado de Minas Gerais. I. Triângulo Mineiro. In: Projeto Algodão. Relatório Anual 73/74. Belo Horizonte, EPAMIG. p. 63-67.

LACA-BUENDIA, J. P. 1975. Contribuição para o conhecimento das ervas daninhas nas principais regiões algodoeiras em áreas de cerrado. Cerrado, Brasília, 6(28): 28-32.

LACA-BUENDIA, J. P. 1977. Contribuição ao conhecimento das ervas daninhas nas regiões algodoeiras do Estado de Minas Gerais. Triângulo Mineiro. In: CONGRESSO NACIONAL DE BOTÂNICA. Anais.... Rio de Janeiro. p. 53-62.

LORENZI, A. J. 1976. Principais ervas daninhas do Paraná. Bol. Tec. IAPAR, Londrina, (2): 208.

MAIA, A. C. (1978). Controle de plantas daninhas. Inf. Agropecu., Belo Horizonte, 4(43): 28-29.

MANI, V. S. et. al. 1968. Losses in crop yield in India due to weed growth. Pans, 14(2): 142-158. 
MARCONDES, D. A. S. et. al. 1981. Herbicidas na cultura convencional. In: MIYASAKAS, S. \& MEDINA, J. C. A soja no Brasil. Campinas, ITAL. p. 544-59.

MONTEIRO, H. DA C. 1958. Malvaceae Mineiras invasoras de Culturas. In: Seminário Brasileiro de Herbicidas e ervas daninhas. Anais. Rio de Janeiro. p. 125-131.

NATIONAL ACADEMY OF SCIENCES 1968. (Comnittee of Plant and Animal Pests). Washington Weed Control.

PEREIRA, H. C. \& JONES, P. A. 1954. A tillage shady in Kenya coffee. Part. I The effects of tillage pratices on coffee yields. Emp. J. Exp. Agric., 22:231-241.

STREET, J. E. et al. 1981. Influence of cotton (Gossypium hirsutum) densisties on competitiveness of pigweed (Amaranthus sp) and sicklepod (Cassia obtusifolia). Weed Science , 29(3): 253-6.

VIANNA, V. de S. 1916. Montes Claros. Belo Horizonte, Imprensa Oficial. 349 p.

VIDAL, M. R. R. \& VIDAL, W. N. 1966. Plantas ruderais de Viçosa. I. Compositae. Experientae, Viçosa, 6(5): 145-266.

VIDAL, M. R.R. 1967. Plantas ruderais de Viçosa II. Chenopodiaceae e Amaranthaceae. Rev. Ceres, Viçosa, 14(78): 45-79.

VIDAL, M. R. R. 1971. Plantas ruderais de Viçosa III. Gramineae. Experientae, Viçosa, 12(2): 34-56.

WARMING, E. 1908. Lagoa Santa. Belo Horizonte, Imprensa Oficial. (Tradução de A. Loefgreen).

ZARECOR, D. 1979. Ipomoea sp. one of the worst weed in soybeans. Agric. News, 1:3-6.

ZEEP, W. V. der. 1971. Consequences of modern weed control for crop growning techniques. Pans. 17(1): 20-25. 


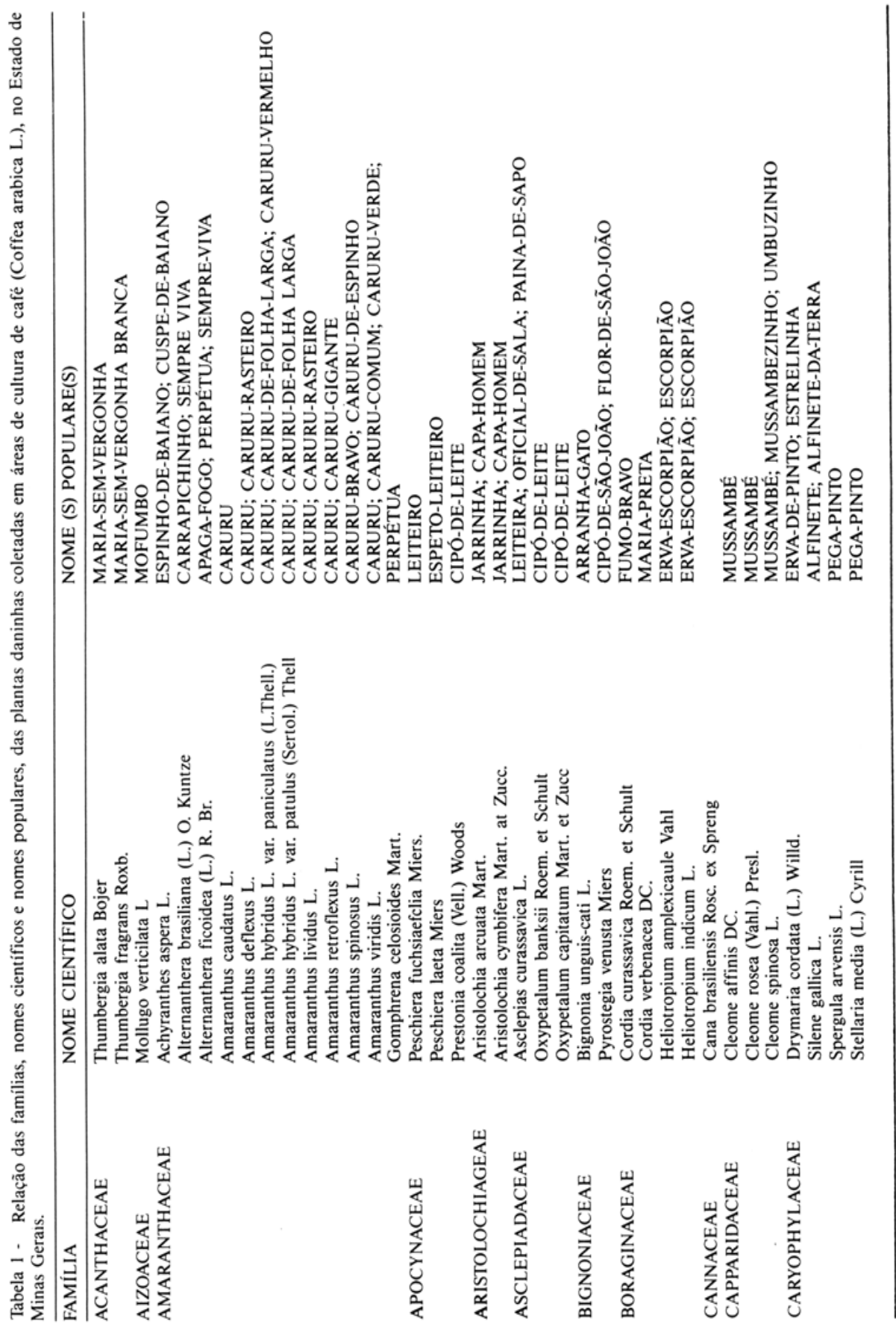




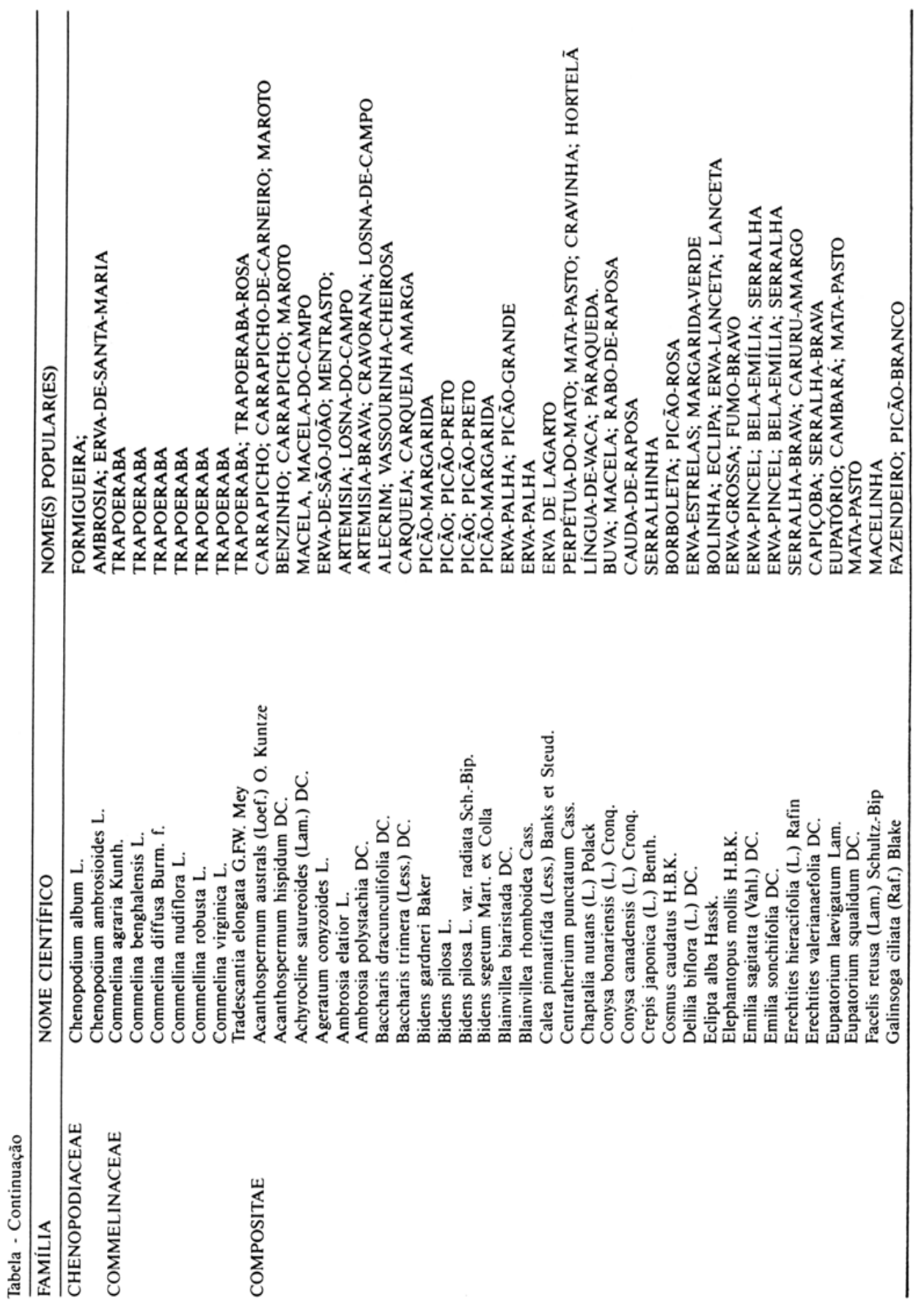




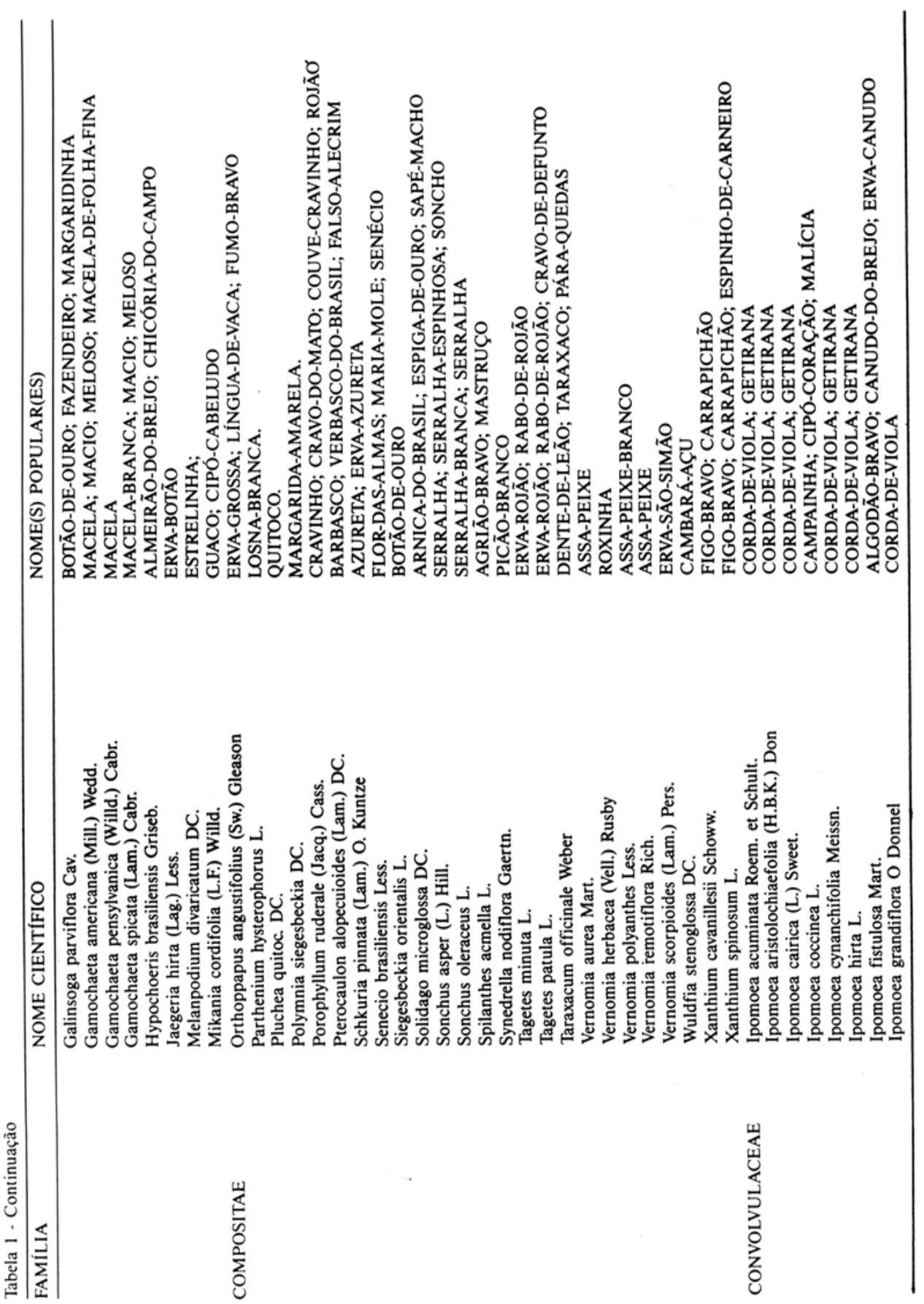




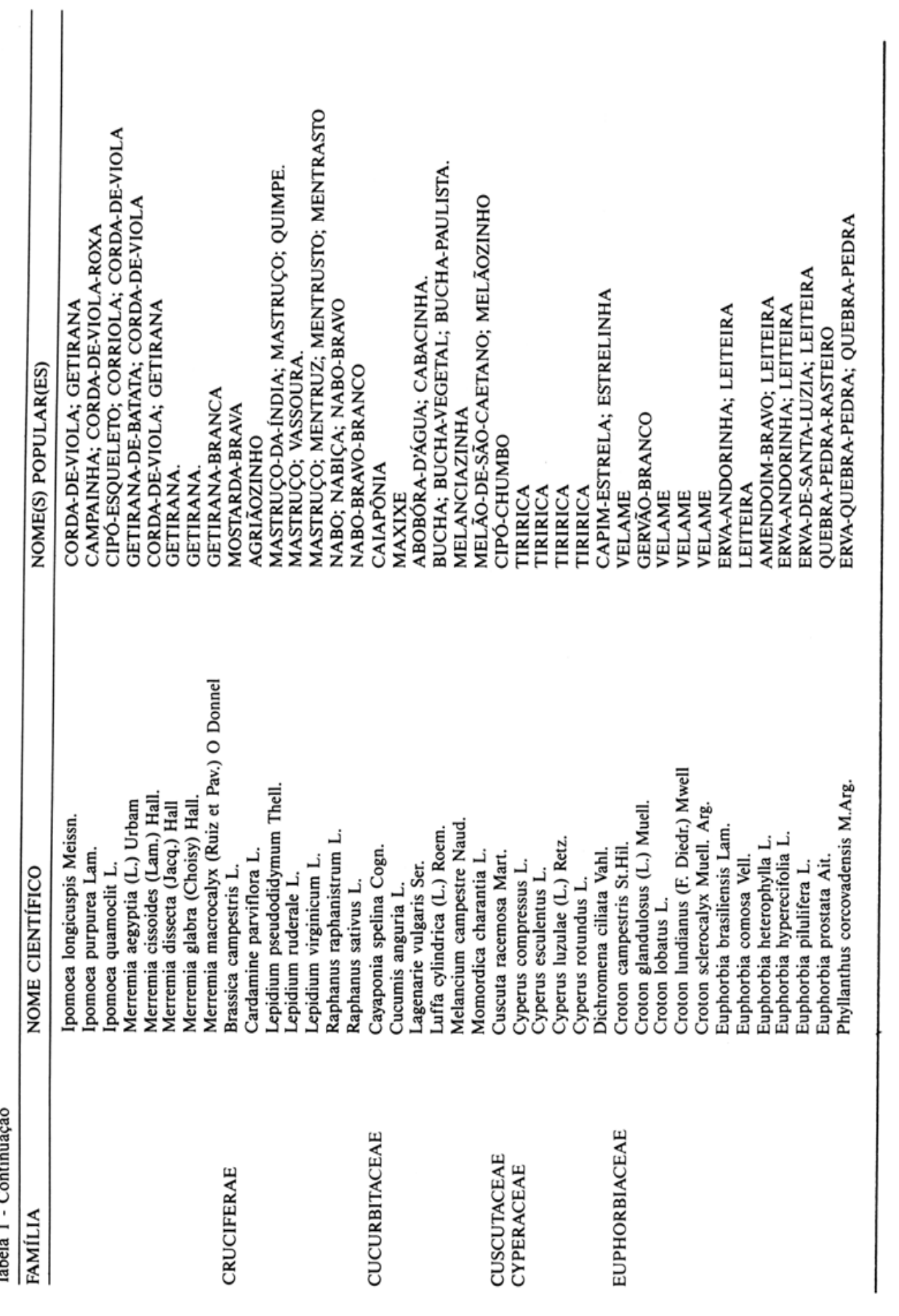




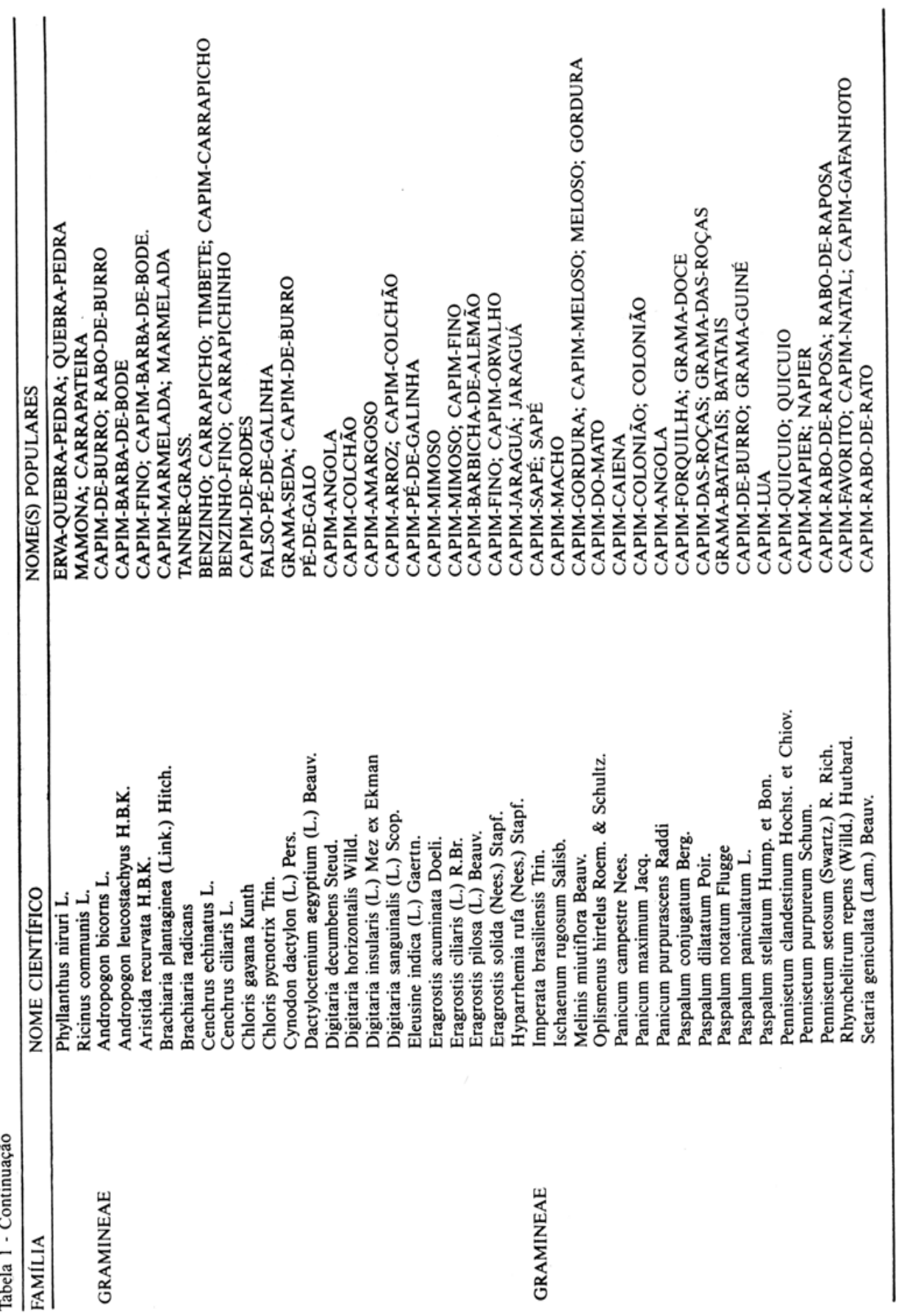




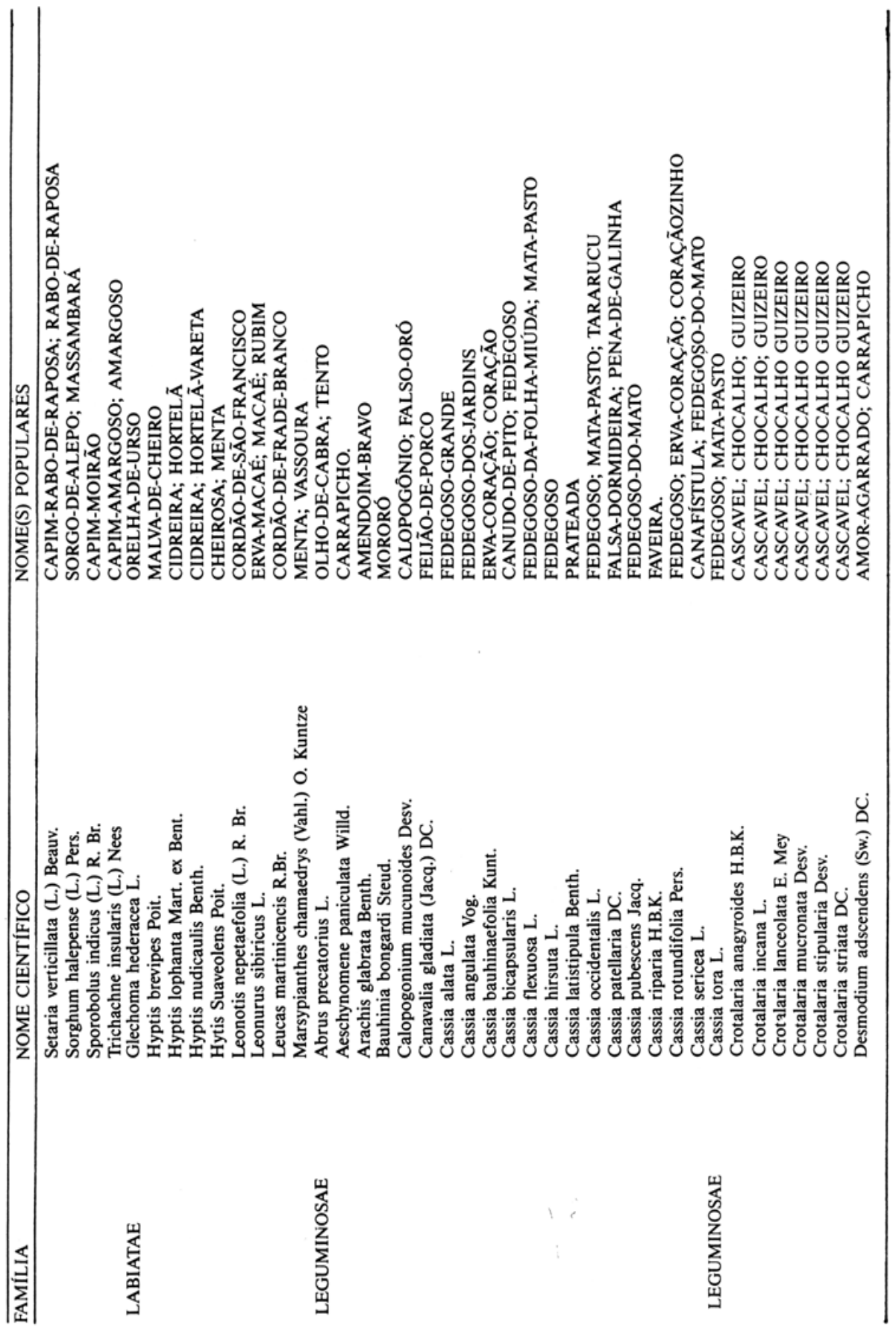




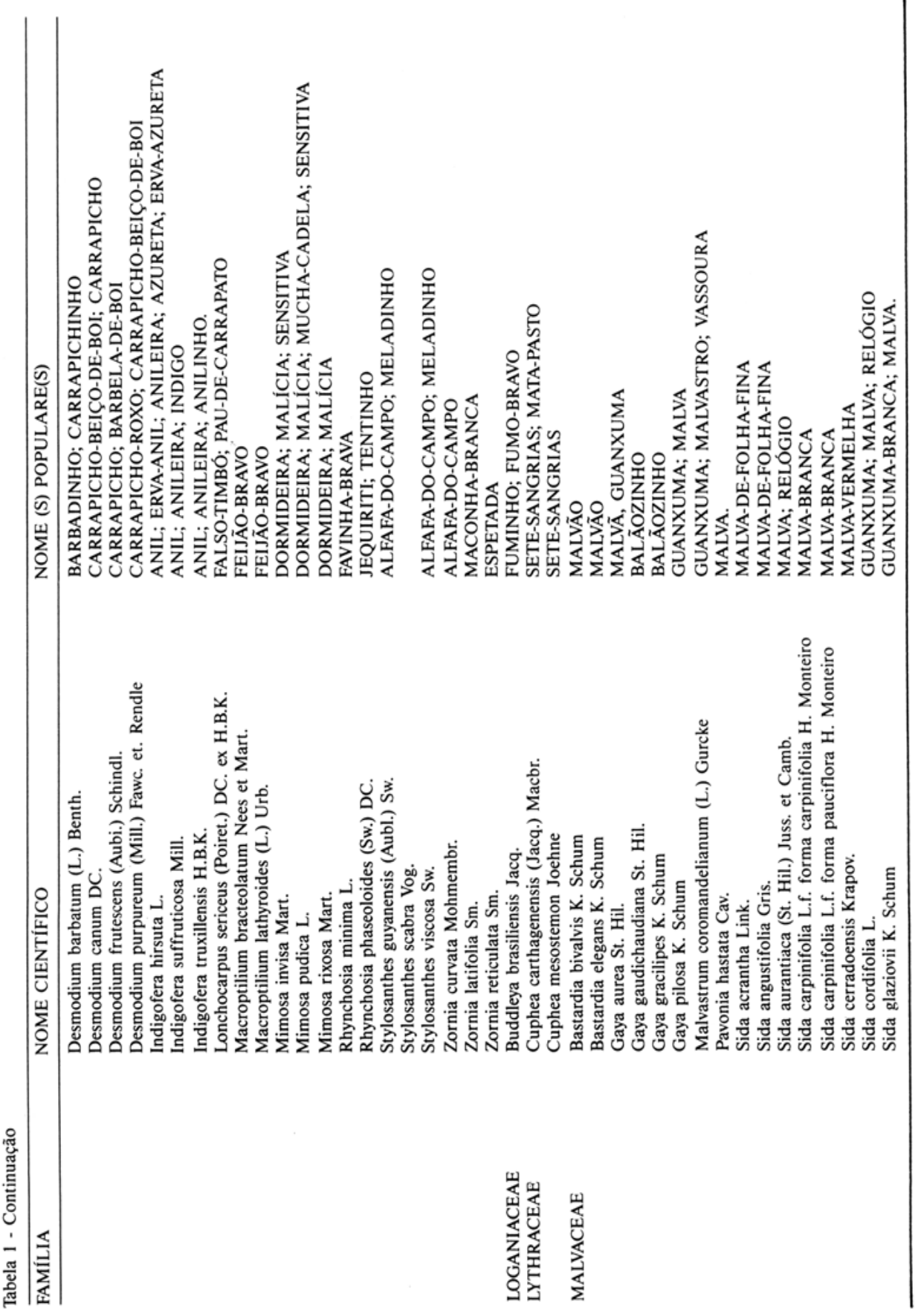




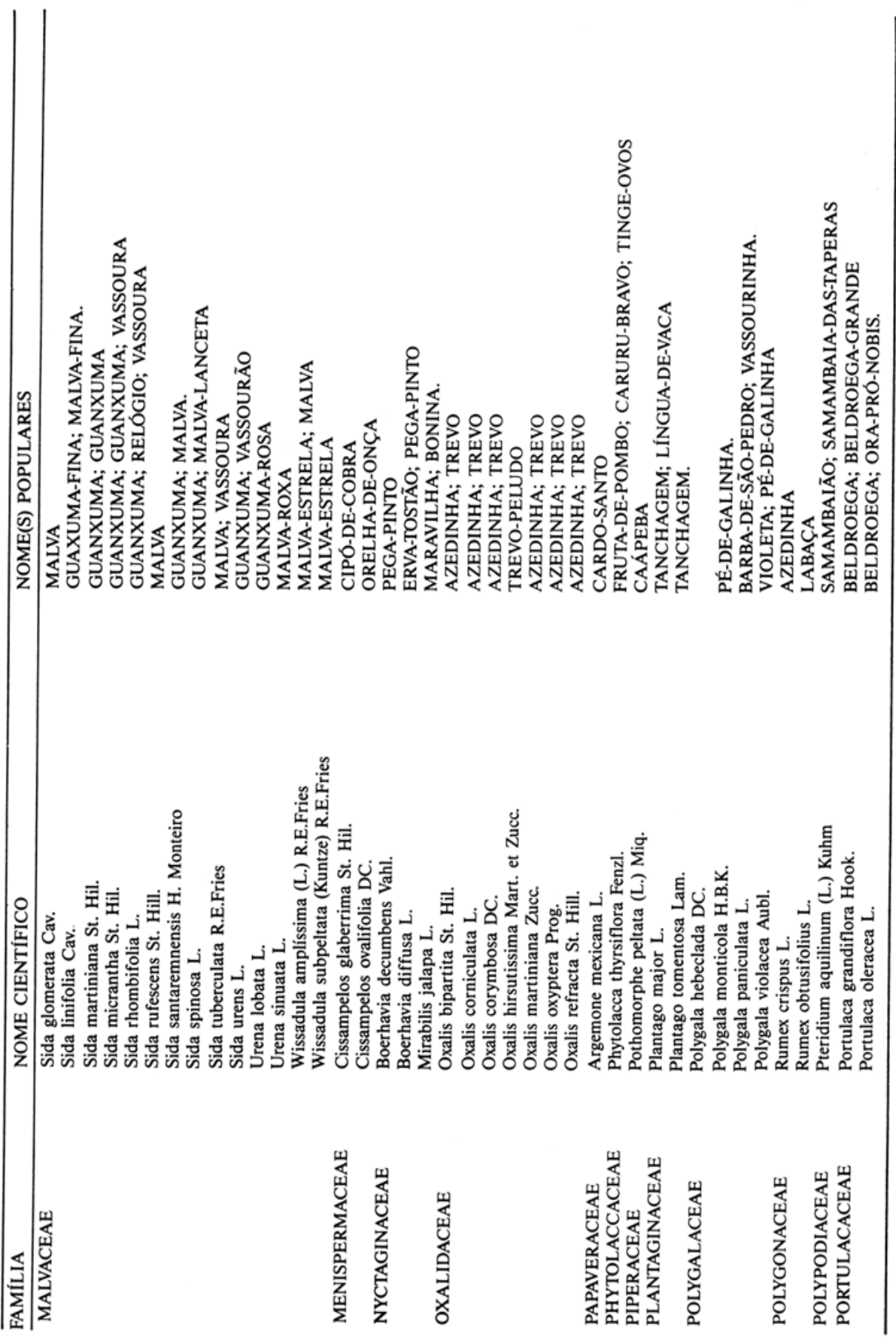




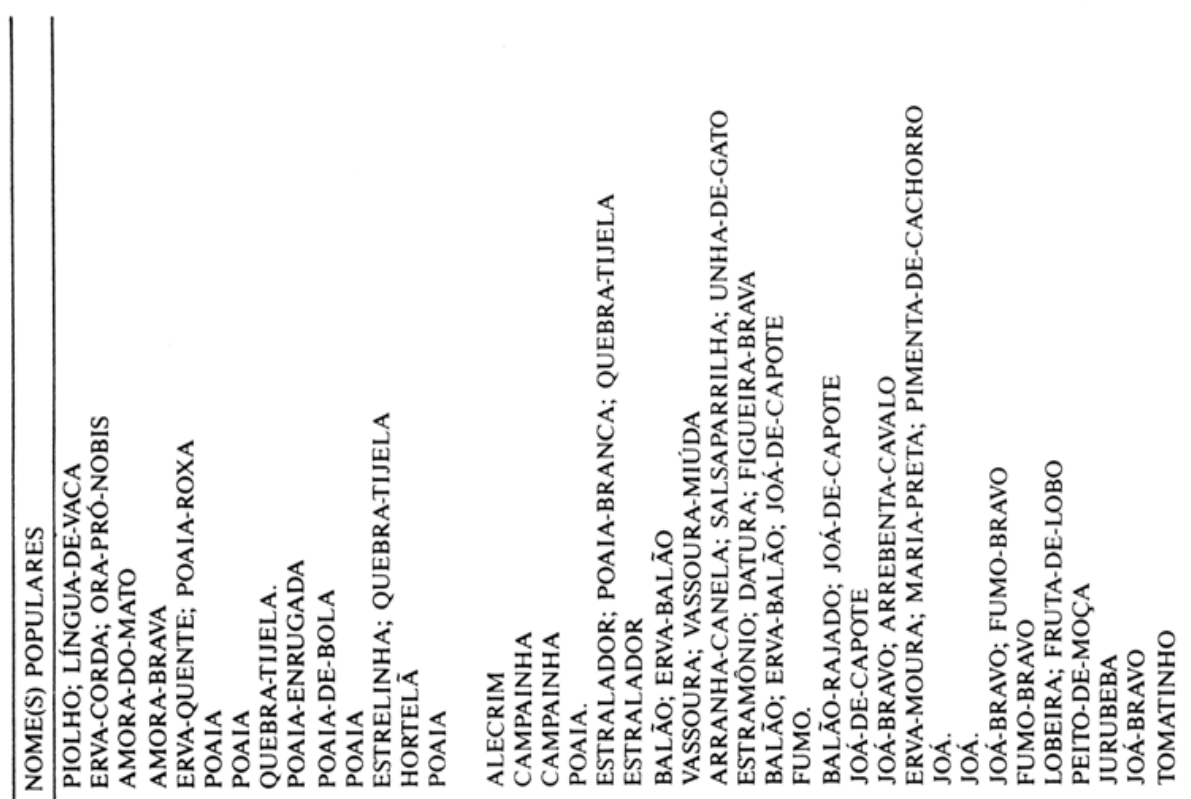

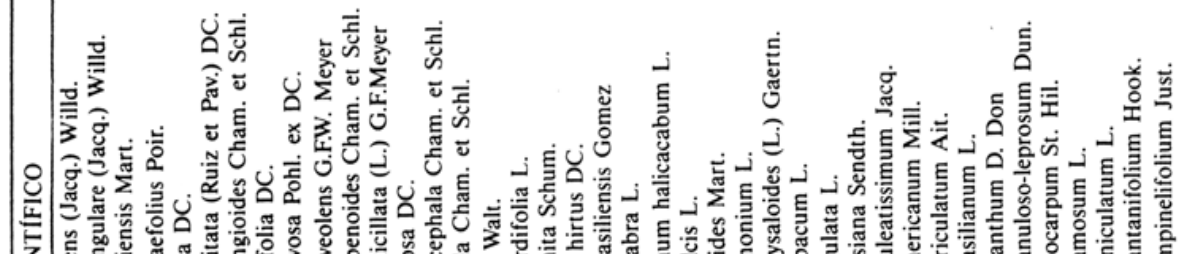

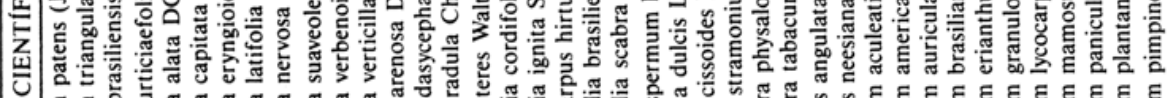

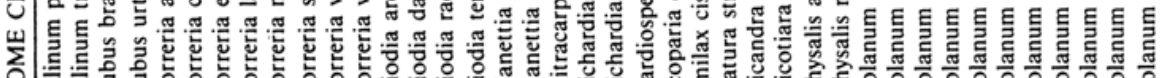

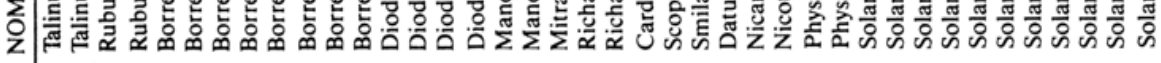
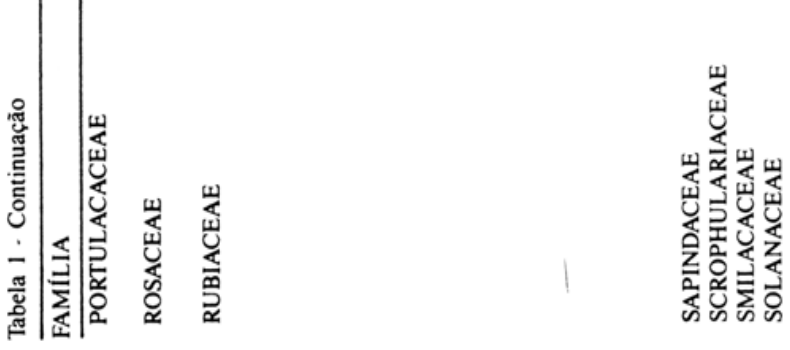


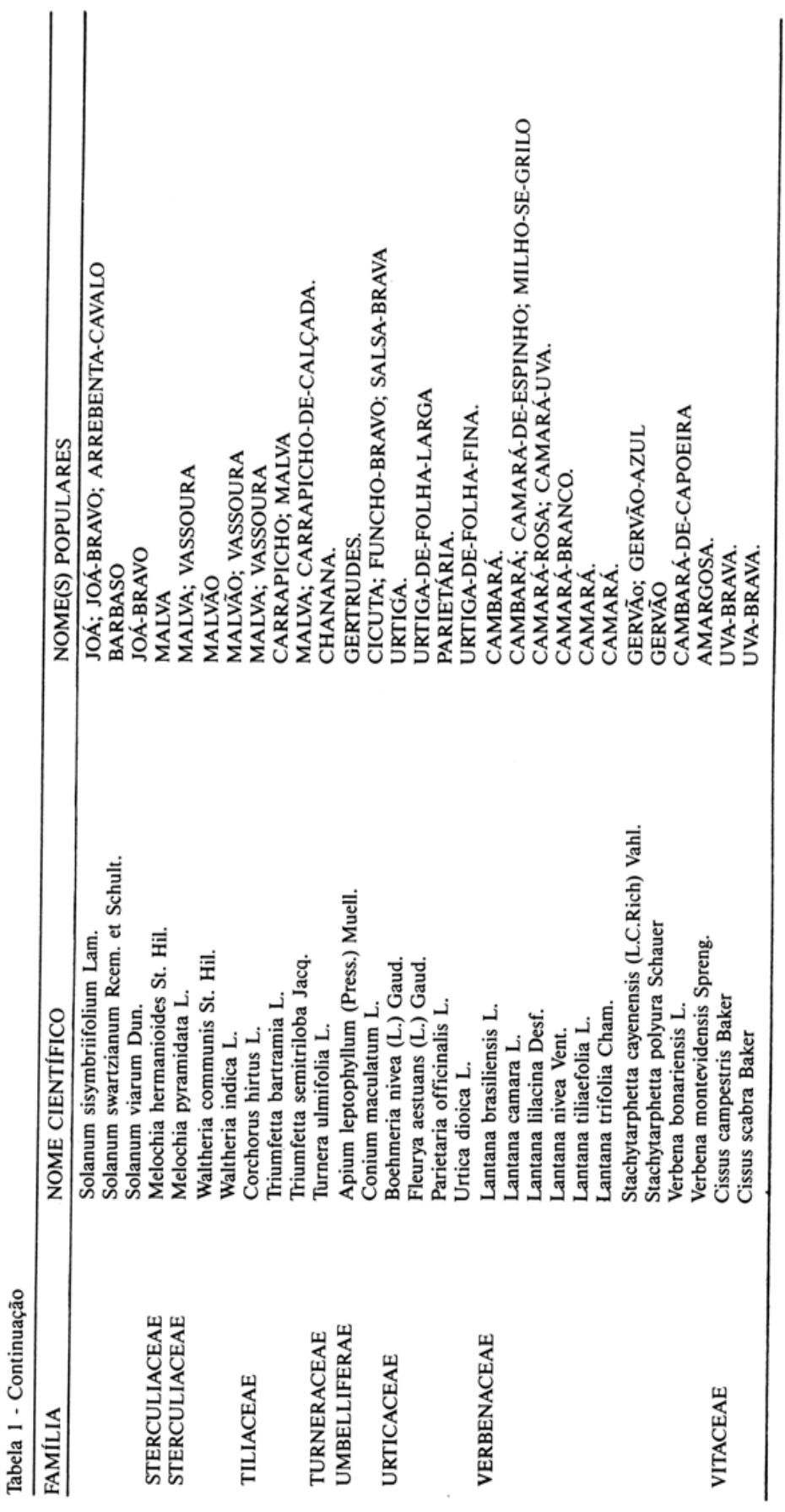


Tabela 2. Relação das familias enfocadas, números de gêneros e espécies.

\begin{tabular}{|c|c|c|}
\hline Família & Gêneros & Espécies \\
\hline Acanthaceae & 1 & 2 \\
\hline Aizoaceae & 1 & 1 \\
\hline Amaranthaceae & 4 & 12 \\
\hline Apocynaceae & 2 & 3 \\
\hline Aristolochiaceae & 1 & 2 \\
\hline Asclepiadaceae & 2 & 3 \\
\hline Bignoniaceae & 2 & 2 \\
\hline Boraginaceae & 2 & 4 \\
\hline Cannaceae & 1 & 1 \\
\hline Capparidaceae & 1 & 3 \\
\hline Caryophylaceae & 4 & 4 \\
\hline Chenopodiaceae & 1 & 2 \\
\hline Commelinaceae & 2 & 7 \\
\hline Compositae & 44 & 65 \\
\hline Convolvulaceae & 2 & 16 \\
\hline Cruciferae & 4 & 7 \\
\hline Cucurbitaceae & 6 & 6 \\
\hline Cuscutaceae & 1 & 1 \\
\hline Cyperaceae & 2 & 5 \\
\hline Euphorbiaceae & 4 & 14 \\
\hline Gramineae & 23 & 42 \\
\hline Labiatae & 6 & 9 \\
\hline Leguminosae & 16 & 48 \\
\hline Liliaceae & 1 & 1 \\
\hline Loganiaceae & 1 & 1 \\
\hline Lythraceae & 1 & 2 \\
\hline Malvaceae & 7 & 30 \\
\hline Menispermanceae & 1 & 2 \\
\hline Nyctaginaceae & 2 & 3 \\
\hline Oxalidaceae & 1 & 7 \\
\hline Papaveraceae & 1 & 1 \\
\hline Phytolaccaceae & 1 & 1 \\
\hline Piperaceae & 1 & 7 \\
\hline Plantaginaceae & 1 & 2 \\
\hline Polygalaceae & 1 & 4 \\
\hline Polygonaceae & 1 & 2 \\
\hline Polypodiaceae & 1 & 1 \\
\hline Portulacaceae & 2 & 4 \\
\hline Rosaceae & 1 & 2 \\
\hline Rubiaceae & 5 & 17 \\
\hline Sapindaceae & 1 & 1 \\
\hline Scrophulariaceae & 1 & 1 \\
\hline Smilacaceae & 1 & 1 \\
\hline Solanaceae & 4 & 19 \\
\hline Sterculiaceae & 2 & 4 \\
\hline Tiliaceae & 2 & 3 \\
\hline Turneraceae & 1 & 1 \\
\hline Umbelliferae & 2 & 2 \\
\hline Urticaceae & 4 & 4 \\
\hline Verbenaceae & 3 & 10 \\
\hline Vitaceae & 1 & 2 \\
\hline Famílias: 51 & Gêneros: 182 & Espécies: 388 \\
\hline
\end{tabular}

